\title{
Colpesto
}

\section{Desinformação na pandemia de Covid-19: similitudes informacionais entre Trump e Bolsonaro}

\author{
Priscila Ramos Carvalho \\ Doutoranda; Universidade Federal do Rio de Janeiro, Rio de Janeiro, RJ, Brasil; \\ carvalho.priscila@gmail.com \\ Paulo César Castro \\ Doutor; Universidade Federal do Rio de Janeiro, Rio de Janeiro, RJ, Brasil; \\ paulo.castro@eco.ufrj.br \\ Marco André Feldman Schneider \\ Doutor; Universidade de São Paulo, São Paulo, SP, Brasil; \\ marcoschneider@ibict.br
}

\begin{abstract}
Resumo: A pesquisa empírica teve como objetivo investigar as possíveis similitudes informacionais entre o ex-presidente dos Estados Unidos e o presidente do Brasil, em virtude do alinhamento político-ideológico entre, respectivamente, Donald Trump e Jair Bolsonaro, que tiveram um posicionamento contraditório no combate à Covid-19. A fim de elucidar a questão de pesquisa, foram coletados dados de postagens nos perfis dos dois no Facebook e os pronunciamentos oficiais nos websites dos governos americano e brasileiro desde o primeiro dia de notificação nos países para realizar a Análise de Conteúdo através do programa IRaMuTeQ, com base no arcabouço teóricoconceitual sobre desinformação. O resultado das análises apresentou similitudes informacionais entre o ex-presidente e o presidente, bem como semelhanças no discurso controverso e em atitudes contrárias às medidas defendidas pela Organização Mundial de Saúde.
\end{abstract}

Palavras-chave: Covid-19. Similitudes informacionais. Desinformação.

\section{Introdução}

A Covid-19, além de um evento médico e sanitário, é também um fenômeno informacional, resultado dos diferentes discursos que sobre ela os atores sociais, individuais e institucionais, produzem. Assim, há a Covid-19 dos especialistas em saúde; a Covid-19 de quem sente no corpo as dores causadas pelo novo coronavírus; a Covid-19 da imprensa e, entre várias outras fontes, a Covid-19 baseada nos mais diferentes discursos que circulam na internet. Desde 2019, quando o primeiro caso foi diagnosticado na cidade de Wuhan, capital da 
província chinesa de Hubei, e a cada dia em que a doença foi se espalhando por outros vários países - levando a Organização Mundial de Saúde (OMS) a anunciar, em 11 de março de 2020, que se tratava de uma pandemia global -, a doença foi tendo vários significados atribuídos a ela.

Na pandemia, a informação passou a ser um recurso imprescindível para os diferentes atores envolvidos no enfrentamento do novo coronavírus, em particular as instituições governamentais e não-governamentais, os profissionais de saúde e a comunidade científica. Numa das pontas do fenômeno informacional, estão os responsáveis pela produção de diferentes tipos de informação a fim de esclarecer as possíveis formas de contágio, prevenção e tratamentos da doença, bem como divulgar os números de casos, de recuperados e de óbitos, além de orientar sobre a distribuição de recursos humanos e financeiros. Na outra ponta, estaria a população, consumidora de informações e diretamente influenciada pelas ações políticas em resposta ao problema de saúde pública. Nessa situação crítica, vale acrescentar a mediação dos fluxos informacionais pelos meios de comunicação tradicionais e pela web, atravessada por diferentes plataformas e redes sociais que proporcionam uma avalanche de dados.

No ambiente digital, a informação ficou mais vulnerável devido ao volume, à velocidade e à variedade de dados produzidos, reproduzidos e compartilhados, propiciando o crescimento de fake news ${ }^{1}$ e a desinformação em um sentido mais amplo. O fenômeno informacional sobre o qual este artigo se debruça compreende a perspectiva do caráter implícito da mediação informacional, levando em conta a imaterialidade da informação e os aspectos sociais, políticos, éticos e as relações de poder, bem como o contexto e o ambiente digital, que interferem na produção de distorções informacionais pelo mau uso e/ou desuso da informação, propiciando uma desordem informacional nos indivíduos consumidores da informação (SANTOS NETO; ALMEIDA JÚNIOR, 2017). Em um quadro de pós-verdade ${ }^{2}$, a disseminação de notícias falsas pode provocar uma onda de desinformação, de negacionismo e de medo na população, contribuindo para o aumento da transmissão do vírus, visto que a 
credibilidade de instituições governamentais, imprensa e ciência tem estado em xeque nos últimos anos.

É sob a consideração desse cenário informacional em que a Covid-19 está inserida - com sua multiplicidade de significações e como objeto de disputa de narrativas - que esse trabalho foi desenvolvido. Mas o foco sobre ela, nessa dimensão, teve uma abordagem ainda mais específica: a construção de sentidos sobre a doença a partir dos discursos de dois atores sociais altamente controversos no cenário político mundial: o ex-presidente dos Estados Unidos, Donald Trump (2016-2020), e atual líder brasileiro, Jair Bolsonaro. Com base no conhecimento prévio sobre o alinhamento político-ideológico e o posicionamento contraditório dos mandatários em relação ao enfrentamento da Covid-19, foi desenvolvida uma pesquisa empírica cujo propósito principal foi investigar se os discursos dos dois estimulam a desinformação sobre a enfermidade e se o fazem através de similitudes informacionais, ou seja, com estratégias e táticas convergentes.

A busca pelas respostas foi realizada em dois conjuntos de discursos produzidos pelos dois representantes políticos: os pronunciamentos oficiais disponíveis nos websites dos seus respectivos governos e as publicações que fizeram em seus perfis no Facebook, no período compreendido entre o primeiro dia de notificação de caso da doença em cada país e 30 de abril de 2020. Os materiais coletados foram submetidos à Análise de Conteúdo, com auxílio do software de análise automática de textos IRaMuTeQ. Antes da análise, entretanto, o artigo apresenta um arcabouço teórico-conceitual sobre estratégias de desinformação que guiará o mapeamento dos contextos semânticos explorados por Trump e Bolsonaro.

\section{A desinformação como estratégia na disputa pelos sentidos da pandemia}

Com todas as particularidades médicas e sanitárias de alcance global, a Covid19 se tornou ainda mais singular por conta dos vários discursos que lhe deram "vida", principalmente para quem não sentiu no corpo as consequências do novo e altamente contagioso coronavírus. Se, tradicionalmente, a percepção sobre as doenças resulta do que sobre elas relatam principalmente os diferentes 
especialistas vinculados ao campo da saúde e, a partir destes, também o fazem os meios de comunicação jornalísticos, qualquer enfermidade agora tem seus significados construídos também levando em conta as informações que circulam pela internet, em especial através dos sites de rede social. Este novo ambiente comunicacional, em que potencialmente qualquer ator social (individual ou institucional) pode produzir e distribuir diferentes conteúdos, ironicamente tem acarretado um aprofundamento progressivo da desinformação.

Não que esse fenômeno seja exclusivo das redes sociais digitais, mas dada a possibilidade de alcance massivo de receptores, informações imprecisas ou mesmo falsas têm tido impactos antes impensáveis. Mais recentemente, elas passaram a ser chamadas genericamente de fake news, expressão que Wardle e Derakhshan (2017, p. 5) preferem não usar, por considerarem que ela não significa devidamente o fenômeno que nomeiam de desordem informacional. Mas também porque ela foi apropriada por políticos de todo o mundo para desqualificar o trabalho jornalístico das organizações que eles acusam de lhes serem desfavoráveis. Além disso, não é incomum que atores sociais que invocam o termo fake news sejam responsáveis, sob os mais diferentes objetivos, também por massivas campanhas de desinformação.

É possível recorrer a Darnton (2014) para mostrar que mentiras, calúnias, difamações e injúrias são táticas bastante antigas, cujas arte e política de ludibriação o autor estudou especialmente nos libelos franceses e ingleses do século XVIII. Outro ponto de partida pode ser observar como os estrategistas militares incorporam táticas de desinformação para alcançar seus objetivos na guerra. No século IV a.C., Sun Tzu, com o clássico A arte da guerra, deixa entrever como a produção da ignorância é parte fundamental das artimanhas de quem se ocupa com o planejamento das ações contra inimigos. A Introdução da obra lançada pela editora WMF Martins Fontes, em que o texto milenar de Tzu é apresentado, revela ainda mais esse aspecto.

[...] a guerra deve ser vista como uma questão de ardil, que cria constantemente falsas aparências, difunde a desinformação e emprega a astúcia e o logro. Quando criadas com imaginação e implementadas com eficiência, o inimigo não saberá onde atacar e tampouco que formações usar, e será, por conseguinte, levado a cometer erros fatais. (TZU; PIN, 2002, p. 31). 
Tratar do tema também é factível analisando as doutrinas militares contemporâneas de países do Ocidente e do Oriente que, além das ações baseadas no poderio bélico, apoiam-se cada vez mais nas estratégias não militares fundadas nas campanhas de desinformação. O general Valery Gerasimov, que empresta o sobrenome para o que seria a atual doutrina militar russa, sinaliza tal perspectiva quando aborda a forma de guerra dos novos tempos:

As próprias "regras da guerra" mudaram. O papel dos meios não militares para alcançar objetivos políticos e estratégicos cresceu e, em muitos casos, excedeu o poder da força das armas em sua eficácia. [...] Tudo isso é complementado por meios militares de caráter dissimulado, incluindo a realização de ações de conflito informativo e as ações das forças de operações especiais. (GERASIMOV, 2016, p. 24, tradução nossa) ${ }^{3}$.

Entre os ardis, estão as informações falsas, a propaganda desestabilizadora, os vazamentos e as ações de hackers, que têm sido alguns dos itens fundamentais na lista de recursos que os militares da Rússia acionam a favor do projeto geopolítico do presidente Vladimir Putin. Não obstante sua posição de maior potência bélica mundial, os Estados Unidos já, há muito tempo, consolidaram sua força também através das ações não militares. Ao terem sob seu domínio o "[...] planejamento e desenvolvimento das redes digitais, principalmente a Internet [...]" (BRITO; PINHEIRO, 2015, p. 145), os usaram de modo que mantivessem e expandissem o seu poder informacional. Brito e Pinheiro (2015) indicam também que a doutrina estadunidense se baseia em três estratégias: disinformation, deception e operações psicológicas. Apesar de terem usos semelhantes, situação que os leva a serem confundidos ou sobrepostos, os termos expressam o objetivo comum “[...] de modificar a percepção de um adversário de acordo com os interesses de quem executa a ação.” (BRITO; PINHEIRO, 2015, p. 147-148).

A indicação das diferenças pelos autores é bastante útil para este trabalho. Se disinformation pode significar o "[...] estado de ignorância do indivíduo em relação ao conhecimento que lhe seria relevante." (BRITO; PINHEIRO, 2015, p. 148) e, por isso, a ausência de informação, em outras acepções fica mais claro o papel de certos atores sociais em deliberadamente 
desinformar. É o que acontece com o que os autores (2015) chamam de informação manipulada e engano proposital.

No primeiro caso, os produtos informacionais de baixo nível cultural seriam usados para imbecilizar as audiências. Tal alienação pode ser comparada ao que Froehlich $(2017$, p. 3), em sua construção de “[...] uma taxonomia para variedades de ignorância - ignorância em si e os modos de informação que a produzem ou facilitam", classifica como "ignorância culturalmente induzida". Para esse método, que “[...] estimula dúvidas sobre as visões corretas já possuídas pelos buscadores de informações" (FROEHLICH, 2017, p. 6), ele usa o neologismo Agnotologia, criado pelo historiador americano Robert N. Proctor, da Universidade de Stanford, para tratar das políticas de produção da ignorância.

Já no engano proposital, Brito e Pinheiro (2015) dão destaque à intenção de, pela deturpação da verdade, induzir ao erro. A leitura dessa tática pode ser feita também com o que Breton (1999) classifica como manipulação, que consiste no mascaramento de uma mensagem, em sua dimensão cognitiva ou afetiva, de modo a vencer a resistência ao conteúdo dela. Quem se vale de estruturas informacionais e tecnológicas para driblar ou paralisar o julgamento do interlocutor, muitas vezes apelando a valores e paixões políticas, tem como meta convencê-lo a crer no que não é verdade.

Vale a pena recorrer ainda a Wardle e Derakhshan (2017), que propõem também os conceitos de misinformation e disinformation. Enquanto o primeiro diz respeito à informação falsa que é compartilhada sem a intenção de causar danos, o segundo refere-se à informação verdadeira, que, tornada pública através de vazamentos, por exemplo, causa prejuízo.

Voltando a Brito e Pinheiro (2015, p. 149-150), passamos a tratar de deception ${ }^{4}$, outro termo em inglês relacionado ao "[...] ato de enganar um adversário, mediante uma ação planejada, e com o uso de um conjunto de métodos $[. .]$.$" ", todos ao mesmo tempo ou em combinações parciais. Ou seja, é$ uma modalidade de desinformação, mas com características peculiares. Entre os métodos de deception, os autores indicam três possibilidades. A primeira é a negação, que consiste no bloqueio do acesso a fontes alternativas de informação que permitam o questionamento de uma falsa realidade. Tal acepção se 
aproxima do que Froehlich (2017) denomina como falta de informação. A segunda é denominada informação verdadeira e está baseada no uso de informações corretas, ou até mesmo parciais, sem grande importância, com o objetivo de reforçar informações falsas. Recorrendo novamente a Froehlich (2017), é possível associar tal método ao que ele classifica como desinformação verdadeira. A diferença principal é que, enquanto Brito e Pinheiro trabalham com conceitos de doutrina militar, Froehlich está mais preocupado com o uso político e corporativo da desinformação. Já a última possibilidade é a do mau direcionamento, no qual a sobrecarga informacional gera dispersão e dificulta o processamento da informação.

Numa descrição formal, Brito e Pinheiro (2015) ilustram uma ação de deception, que combina negação e desinformação, nos seguintes termos:

[...] ao operar com negação informacional, tenta-se negar ao alvo da ação o acesso a informações precisas sem que este saiba [...]. Em paralelo, opera-se com desinformação que por sua vez se relaciona ao esforço de fazer com que o adversário acredite em informações falsas [...]. Negação e desinformação são, portanto, prescritos para atuarem concomitantemente a partir do escopo abrangente de uma operação de decepção, de forma a conduzir a visão do alvo para a paisagem que se quer apresentar, impedindo o olhar deste para outras passagens que poderiam pôr em xeque o cenário de desinformação pretendido. Cabe destacar que com tal sofisticação de recursos utilizados as operações de decepção são de difícil detecção até mesmo por especialistas no campo informacional. (BRITO; PINHEIRO, 2015, p. 150).

Por fim, como parte das operações de informação que os Estados Unidos colocam em prática para manter e aumentar sua hegemonia internacional, Brito e Pinheiro (2015) elencam as operações psicológicas. O que as faz serem diferentes da deception é o tamanho do alvo que se pretende atingir com a desinformação, buscando-se alcançar não mais alguns poucos indivíduos, mas um grupo social ou até mesmo a população inteira de um país. Se tais técnicas, tipicamente militares, eram antes usadas principalmente por Estados, capazes de acionar diferentes dispositivos comunicacionais para fazer circular conteúdos enganosos e afirmarem seus poderes informacionais com a web, essa habilidade também se tornou disponível para qualquer ator individual ou institucional. Com o uso massivo dos sites de rede social, as técnicas anteriores foram 
impulsionadas e novas surgiram, aproveitando-se de recursos típicos da internet, como bots, trolls, cyborgs, cyberbullying, click farms etc.

As estratégias aqui elencadas, que são usadas para confundir e induzir o interlocutor ao erro, devem ser consideradas também de acordo com as motivações que as levam a ser acionadas, baseadas em interesses econômicos, políticos, psicológicos, ideológicos, religiosos, entre vários outros. É necessário ainda levar em conta a tipologia dos agentes por trás das campanhas de desinformação, podendo ser atores oficiais, como serviços de inteligência, partidos políticos, empresas de modo geral, inclusive as jornalísticas e de relações públicas etc., ou atores não oficiais, a exemplo de indivíduos ou grupos que se reúnem improvisadamente em torno de interesses comuns (WARDLE; DERAKHSHAN, 2017). Há ainda a possibilidade do ator social que, mesmo vinculado a uma instituição, pode agir individualmente, como consideramos os casos do atual presidente do Brasil, Jair Bolsonaro, e do ex-presidente americano, Donald Trump.

O cenário que congrega técnicas de produção de conteúdos falsos por certos atores sociais, que os fazem circular massivamente através das mídias sociais a fim de alcançar objetivos escusos, contribui para acrescentar elementos novos ao conceito de regime de verdade de Foucault (1979, p. 12), caracterizado como o "[...] conjunto das regras segundo as quais se distingue o verdadeiro do falso e se atribui ao verdadeiro efeitos específicos de poder [...].”. No regime de informação que vem se estabelecendo a partir do ambiente comunicacional da internet, o limite entre o verdadeiro e o falso passa a ser maliciosamente tênue, pois as tradicionais instituições e seus protocolos de construção de "verdades" ciência, jornalismo, universidade, judiciário etc. - são constantemente colocadas em xeque. Em ambas as situações, a busca pela instituição do "discurso de autoridade", como proposto por Bourdieu (2008, p. 91), acarreta, com ardis ou não, efeitos concretos de poder.

A partir dos conceitos de "regime de verdade" de Foucault (1979) e "regime de informação" de González de Gómez $(2012)^{5}$, é possível inferir que a sociedade atual é permeada de um regime de desinformação, envolvendo uma gama diversa de atores, sujeitos, infraestrutura, tecnologia, política, cultura e 
poder, que usa táticas complexas de linguagem e comunicação na disseminação de notícias falsas através de canais de informação e redes sociotécnicas visando à construção de um ambiente de desordem informacional em prol de certos interesses. Nesse sentido, geram um regime de incerteza suportado por uma corrente encadeada de informações falsas inerentes que reforçam crenças, estimulam comportamentos, moldam discursos e produzem (des)autoridade.

Nessa luta, a Covid-19 é significada e ressignificada, sendo objeto de disputa entre os mais distintos agentes. Se, de um lado da arena discursiva, pode estar a OMS, do outro, criticando e colocando em dúvida as orientações da instituição, pode estar o presidente do país mais poderoso do mundo. A doença é objeto então de uma verdadeira infodemia, “[...] um excesso de informações, algumas precisas e outras não, que tornam difícil encontrar fontes idôneas e orientações confiáveis quando se precisa." (ORGANIZAÇÃO PANAMERICANA DA SAÚDE, 2020, p. 2). As informações, assim como o novo coronavírus, se alastram muito rapidamente, e, no caso das imprecisas e das falsas, as consequências podem ser o descumprimento das orientações sanitárias - uso de máscara, distanciamento social e higienização -, o desdém e a negação em relação aos sintomas, o uso de tratamentos e medicamentos não aprovados por especialistas em saúde, podendo todas elas culminar no aumento de casos e de mortes.

O trabalho de verificação feito pela agência de notícias Agence FrancePresse - AFP Fact Check $^{6}$ - sobre 405 conteúdos falsos que abordavam a Covid-19 veiculados entre janeiro e abril de 2020 mostrou que a maioria se enquadra como informações falsas relacionadas a receitas para prevenção ou curas não verificadas e com teorias da conspiração não comprovadas. No primeiro grupo, foram encontrados conselhos para prevenir o contágio com a ingestão de vitamina D; para curar, gargarejo com água e sal; e, para matar o vírus, o uso de luz, cloro e altas temperaturas. A AFP mostrou também que, de autoria do ex-presidente Trump, circulou a falsa informação de que a injeção de desinfetante poderia matar o novo coronavírus (2020). Já no caso das teorias conspiratórias, circulam especulações sobre a criação do vírus em laboratórios dos Estados Unidos e da China e sobre a morte de um voluntário britânico 
depois que havia sido vacinado, ainda que esta sequer tivesse sido criada na época.

No Brasil, no mesmo período, circularam 329 conteúdos falsos, de acordo com checagem feita pela Latam Chequea, projeto da Fundación La Voz Pública ${ }^{7}$. O destaque, assim como no trabalho da AFP, foi para: a) informações sobre prevenção, cura, tratamentos e medicamentos - com a indicação de remédios caseiros para gripe comum, como tomar mel, e dos medicamentos cloroquina, hidroxicloroquina, azitromicina e ivermectina, "receitados" inclusive pelo presidente Bolsonaro; b) teorias da conspiração - questionamento da eficácia da proteção de máscaras, com destaque para o alerta sobre máscaras chinesas infectadas pelo vírus, e da atuação da OMS, que estaria a favor da aprovação de uma vacina chinesa, ao custo de US\$ 10 mil por dose, e contra uma vacina americana de custo mais baixo. Convém citar ainda a produção de algumas informações "falsas positivas", como a de que o Banco Mundial teria classificado o Brasil como o melhor país no combate à Covid-19 e, através de gráficos, a demonstração de que o vírus teria matado menos que outras doenças.

\section{Do IRaMuTeQ à Análise de Conteúdo: métodos computacionais a serviço da busca pelos sentidos dos textos}

A pesquisa de caráter exploratório teve como objetivo investigar as estratégias informacionais usadas por Donald Trump e Jair Bolsonaro quando se referiram à Covid-19, no período entre a notificação do primeiro caso da doença em cada um dos países - 21 de janeiro de 2020 nos Estados Unidos e 25 de fevereiro de 2020 no Brasil - e 30 de abril do mesmo ano. A hipótese que orienta este trabalho é que os mandatários adotaram uma abordagem similar e, conforme sustentado teoricamente, contribuíram com a desinformação sobre a doença.

O estudo empírico foi realizado em duas etapas, divididas em: 1) coleta de dois conjuntos de dados, sendo a) postagens nos perfis de cada um dos presidentes no Facebook e b) pronunciamentos oficiais nos websites dos governos estadunidense e brasileiro; 2) Análise de Conteúdo orientada por Bardin (2016), com auxílio do IRaMuTeQ. 
A coleta das postagens no Facebook foi realizada no dia 10 de maio de 2020 através dos programas gratuitos Facepager e Web Scraper. Em paralelo, foram recuperados 36 pronunciamentos de Donald Trump disponíveis no website da Casa Branca (em inglês White House), bem como seis pronunciamentos de Jair Bolsonaro disponibilizados no website oficial do governo brasileiro. Os dois conjuntos de discursos de cada um dos enunciadores guardam particularidades importantes para a análise, pois foram enunciados sob condições de produção e em ambientes comunicacionais diferentes, além de serem consumidos por público diversificado. As manifestações de presidentes de países, independentemente do ambiente em que acontecem, sempre serão objeto de amplo interesse dos meios de comunicação de massa, principalmente aquelas proferidas nos websites de rede social. Entretanto, as repercussões midiáticas dos discursos não fazem parte do material de análise dessa pesquisa.

A partir dessas considerações, na Análise de Conteúdo, foram organizados dois corpora textuais com postagens no Facebook e os pronunciamentos oficiais. Para submetê-los à ferramenta, foi necessário cumprir exigências como o tratamento dos textos (retirada de acentos, pontos etc.), sinalização com asteriscos para relacioná-los aos autores dos discursos (*** *Trump e ****Bolsonaro) e gravação em arquivos de extensão de texto (txt).

O IRaMuTeQ é um software de código aberto e gratuito, criado em 2009 por Pierre Ratinaud, da Universidade de Toulouse, com o objetivo de quantificar as estruturas contidas em um determinado texto, permitindo análises textuais ancoradas nas linguagens estatísticas $\mathrm{R}$ e Python, tendo como vantagem a capacidade de analisar diferentes corpos textuais mediante interpretação do pesquisador (CAMARGO; JUSTO, 2013).

\section{Entre o oficial e o extraoficial: convergências de conteúdo e forma nos discursos de Trump e Bolsonaro}

Os discursos de Trump e Bolsonaro serão analisados a seguir separadamente; primeiro, os pronunciamentos e, depois, as postagens no Facebook, de modo que sejam identificadas marcas temáticas e formais nos respectivos conteúdos. Espera-se, assim, demonstrar o que há de similitudes e diferenças entre as táticas 
de desinformação dos mandatários ao abordarem a Covid-19 no período escolhido.

\subsection{Pronunciamentos de Trump: os discursos na Casa Branca}

Da estatística simples aplicada ao conjunto de pronunciamentos oficiais de Donald Trump, o IRaMuTeQ encontrou 8.464 segmentos de texto (ST), 347.007 ocorrências (palavras), 9.600 formas, 6.545 formas ativas (substantivos, adjetivos e advérbios) e 732 formas suplementares (artigos definidos, pronomes, conjunções etc.). A aplicação da técnica de Classificação Hierárquica Descendente $(\mathrm{CHD})^{8}$ sobre os textos gerou o dendrograma exibido na Figura 1, no qual os ST são organizados em quatro classes. Essa segmentação, a partir dos quatro conjuntos de léxicos agregados, automatiza o trabalho de categorização que o pesquisador precisaria fazer ao lidar com os conteúdos e aponta as correlações entre os diferentes discursos produzidos nos encontros oficiais com jornalistas na Casa Branca.

Figura 1 - Dendrograma de Pronunciamentos de Trump

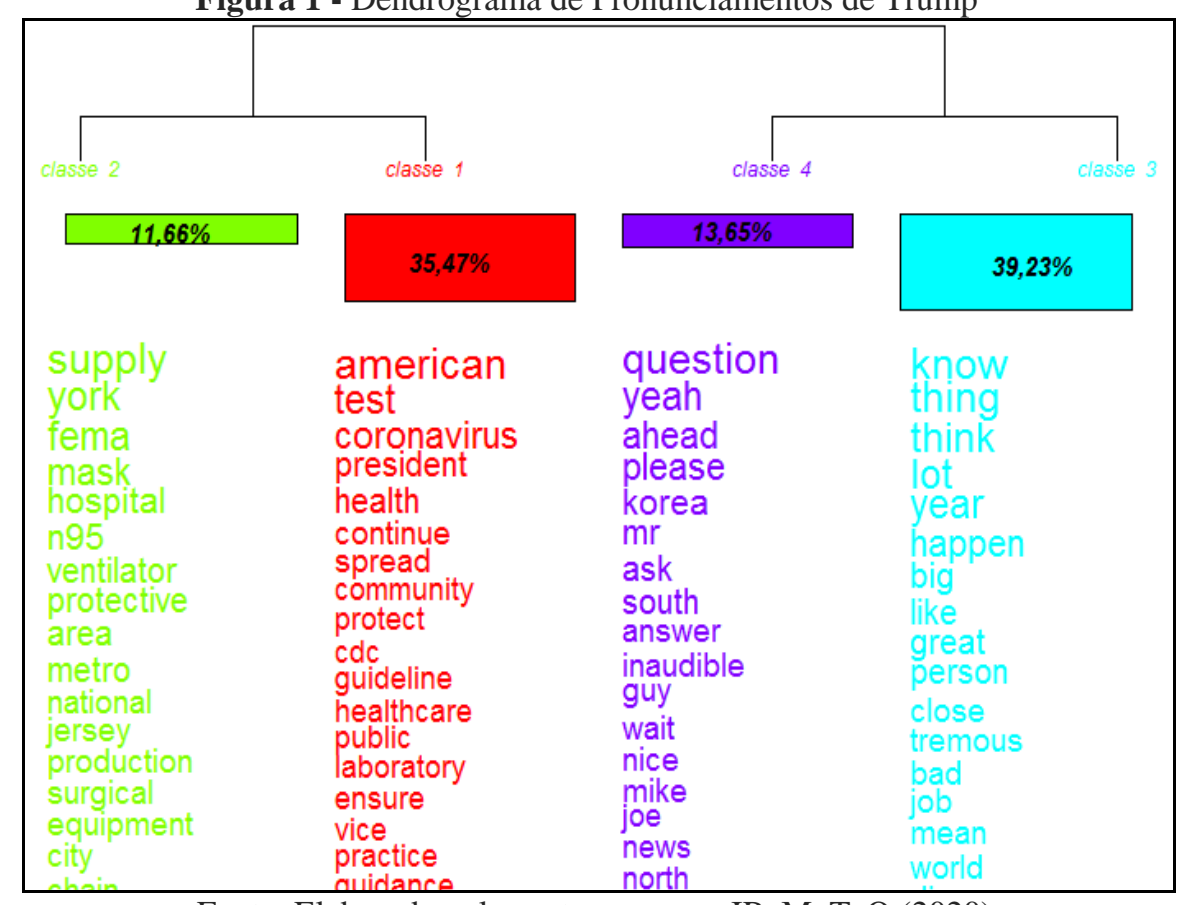

Fonte: Elaborado pelos autores com o IRaMuTeQ (2020).

A classe 1, representada pela cor vermelha e com o segundo maior percentual de ST $(35,47 \%)$, reúne trechos que refletem o modo como o então presidente americano se apresenta como governante preocupado em evitar a 
propagação do coronavírus e como é capaz de agradecer pelo esforço dos profissionais na linha de frente do combate à doença. Uma de suas ações - o resgate de americanos que se encontravam fora dos Estados Unidos e com dificuldade de voltar ao país, logo no início da pandemia - foi recorrentemente citada como exemplo de que estava fazendo um bom trabalho e para confrontar seus críticos, inclusive na sua batalha contra a OMS:

a) "Esta escala mundial dos nossos esforços de repatriação não tem paralelo na nossa vida. [...] Estamos trabalhando com eles para que o povo americano volte a estar com suas famílias". 9

Ainda como parte de sua atuação, anuncia medidas relacionadas a medicamentos cuja eficácia não tinha sido comprovada cientificamente:

b) "28 milhões de comprimidos de hidroxicloroquina foram enviados para todo o país a partir do Estoque Estratégico Nacional”.

Tal ato governamental dá concretude aos discursos, principalmente no Facebook (como será visto mais adiante), com os quais o presidente defendeu o uso de alguns medicamentos. Consumida por um público leigo e considerando a importância do agente responsável por ela, a informação pode ser classificada como marca de Agnotologia, pois provoca dúvidas diante das recomendações dadas por especialistas do campo da saúde, e como desinformação verdadeira, na medida em que, com uma verdade factual (o envio da hidroxicloroquina), há o reforço de uma desinformação (os benefícios do remédio).

A pandemia é ressemantizada quando associada a uma guerra, e, se há uma guerra, cujos esforços são muito maiores do que em tempos de paz, há um comandante à frente dela. Apesar do uso do pronome pessoal no plural (nós) que pode incluir os médicos ou a população do país -, a marca personalista do governo de Trump não deixa dúvidas, na maioria de suas falas, sobre quem chefia:

c) "Temos que nos livrar - quer dizer, nossa grande guerra não é um - não é uma guerra financeira. É uma guerra - é uma guerra médica. E temos que vencer esta guerra".

A classe 2 (em verde) reúne 11,66\% segmentos de texto, que reforçam o caráter institucional dos enunciados. Não por acaso o dendrograma demonstra 
que ela está próxima da classe 1. As falas tratam principalmente das ações de órgãos do governo federal e da relação com os gestores dos Estados, exemplificadas pelos dois enunciados a seguir:

d) "Em poucos dias, entregamos quase 11 milhões de máscaras N95 a pontos de acesso em todo o país, como você sabe, incluindo 6,6 milhões para Nova York e Nova Jersey, 1,8 milhão para Chicago, 1,7 milhão para Detroit e 837.000 para Nova Orleans".

e) "E eu direi a você, como um não cientista aqui em cima, que vejo vislumbres de esperança nos primeiros números que estamos vendo saindo da área da Grande Nova York, em Nova Jersey, até mesmo Nova Orleans e Detroit, e Chicago”.

Se o enunciado "d" é uma prestação de contas das ações realizadas pelo governo central, o "e" seria a consequência, positiva, do que foi feito, segundo avaliação do próprio presidente. Como no período avaliado os números de casos e mortes por Covid-19 cresceram progressivamente, o entusiasmo do "comandante da guerra", ainda que reconheça que não é um cientista, parece não condizer com a realidade. Por isso, pode representar uma deturpação da verdade. Ainda que não seja uma mentira explícita, a fala, dada a força de autoridade do enunciador, pode ser um incentivo para que as pessoas acreditem no refluxo da pandemia.

A interligação das classes 3 (em azul) e 4 (em roxo), com seus respectivos $39,23 \%$ e $13,65 \%$ de ST, pode ser explicada pelas temáticas fortemente políticas que lhes caracterizam. Para entender em que contexto são pronunciados, é preciso lembrar que, no período que é objeto da pesquisa, Trump foi alvo de um processo de impeachment, do qual se livrou no Senado, e também estava em plena campanha pelo segundo mandato presidencial. A disputa orienta suas manifestações sobre o coronavírus na medida em que elas demarcam os inimigos que precisa combater, sejam eles externos (OMS, China) ou internos (Barack Obama, Joe Biden, partido Democrata e a mídia que lhe é crítica, chamada de lamestream - algo como "imprensa manca", "coxa", em oposição a mainstream - e acusada de produzir fake news):

f) “A OMS, que é a Organização Mundial da Saúde, recebe grandes quantias de dinheiro dos Estados Unidos. E nós pagamos pela maioria - a maior parte de seu dinheiro. E eles realmente criticaram e discordaram da minha proibição de viajar na época em que fiz isso". 
g) "Acho que estamos fazendo um trabalho extraordinário. Se você olhar - se você olhar, digamos, o H1N1 - você olhar para aquele todo - isso foi um desastre. Foi um período difícil para o nosso país".

A referência ao vírus H1N1 em "g" é uma forma de reprovar a atuação do governo Obama durante aquela pandemia e, consequentemente, do seu então vice-presidente Biden, e, ao mesmo tempo, comparar com a sua gestão diante da Covid-19, classificada por ele mesmo invariavelmente como great (ótima). Assim como em "f” e "g", no enunciado a seguir, a tática de desinformação também é usada para confundir, gerando dúvidas e questionamentos. No caso de "h", o prognóstico minimiza as mortes e a Covid-19 é tratada como uma enfermidade menor:

h) "Estamos no meio de uma temporada de gripe forte. Você sabe, tivemos uma temporada ruim no ano passado como exemplo. Uma temporada de gripe forte. E você terá 35-, 36-, 37.000 pessoas mortas, às vezes mais, às vezes menos”.

\subsection{Trump no Facebook: a Covid-19 sob a lógica da disputa política}

As postagens do presidente americano no Facebook, ao serem avaliadas estatisticamente pelo IRaMuTeQ, resultaram em 462 ST, 18.941 ocorrências, 3.359 formas, 2.410 formas ativas e 426 formas suplementares. Dos ST, quando usado o método de $\mathrm{CHD}$, foi gerado um dendrograma composto por quatro classes, retratadas na Figura 2.

Figura 2 - Dendrograma de Postagens de Trump no Facebook

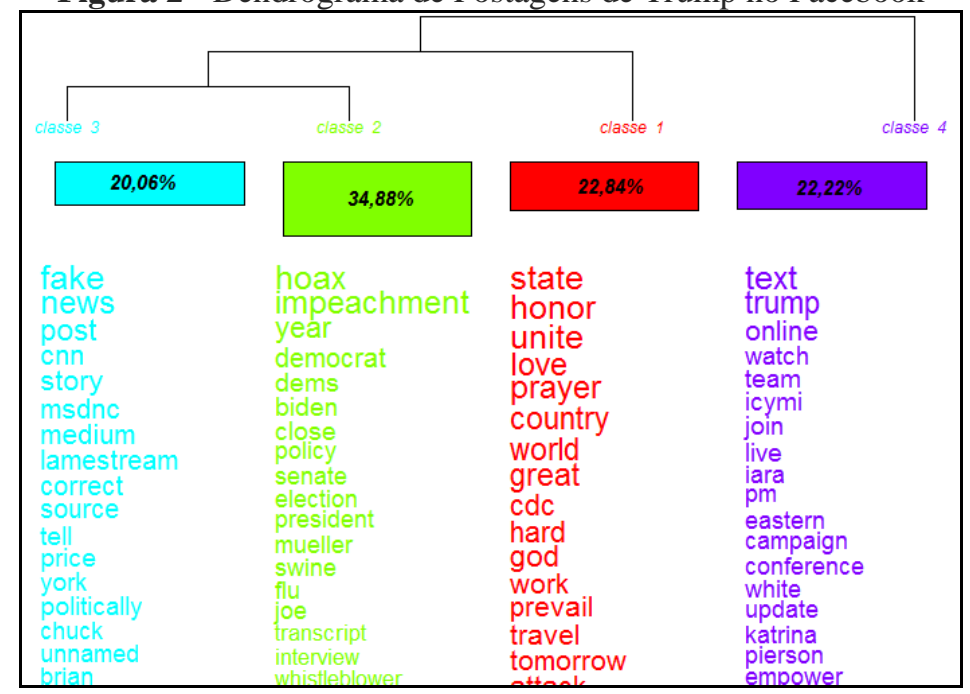

Fonte: Elaborado pelos autores com o IRaMuTeQ (2020). 
A categorização dos enunciados publicados no site de rede social, ainda que sob outra condição de produção discursiva, mostra que os campos lexicais acionados por Trump são muito próximos dos encontrados nos pronunciamentos. Parecem ser, portanto, o reforço de contextos semânticos cujos sentidos se entrelaçam de uma situação a outra. As classes 2 (verde), 3 (azul) e 4 (roxo), que, somadas, representam o maior percentual dos ST (respectivamente $34,88 \%, 20,06 \%$ e $22,22 \%$ ), revelam significantes verbais convergentes com as classes 3 e 4 do dendrograma da Figura 1, nos quais o processo de impeachment - como visto no enunciado "i”" a seguir - e a disputa eleitoral com o ex-vice-presidente Joe Biden são a tônica. A maioria dos ST voltados a essas temáticas, tanto no primeiro dendrograma quanto neste, revela que, enquanto cresciam os casos de Covid-19 pelo país, o presidente ainda estava remoendo o que chamou de "embuste" e dando mais atenção à corrida pelo seu segundo mandato. Se a pandemia surge nessas classes, é mais para anunciar os inimigos contrários ao seu esforço de combatê-la, o que reforça o objetivo político dos enunciados. É o que ele faz quando ataca os governadores, pois estes, ao responsabilizarem o governo federal pelo crescimento de casos de Covid-19 no país, estariam produzindo notícias falsas a partir de suas próprias incompetências, como visto no enunciado “j””. Ou no falso embate com as administrações estaduais sobre qual instância de governo poderia determinar os lockdowns, revelado em " $\mathrm{k}$ ":

i) "Depois de ter sido tratado de forma incrivelmente injusta na Câmara, e então ter que suportar hora após hora de mentiras, fraude e engano por Shifty Schiff, Chuck Schumer e sua equipe, parece que meus advogados serão forçados a começar no sábado, que é chamado de Vale da Morte na TV".

j) "JB Pritzker, governador de Illinois, e um grupo muito pequeno de alguns outros governadores, junto com a Fake News CNN \& Concast (MSDNC), não deveriam culpar o governo federal por suas próprias deficiências. Estamos lá para apoiá-lo se você falhar, e sempre estaremos!".

k) "É preciso lembrar que os governadores queriam ter controle total sobre a abertura de seus estados, mas agora querem que nós, o governo federal, façamos os testes".

Se, no Facebook, o então presidente teve mais liberdade para definir sua narrativa política, inclusive para acusar alguns veículos de imprensa de produzir fake news - enunciado "l" -, nas conferências de imprensa da Casa Branca, 
ainda que sob sua batuta, ele precisou responder às perguntas de interesse dos jornalistas. $\mathrm{O}$ menor volume de percentuais das classes 3 e 4 na Figura 1 $(52,88 \%)$ em relação aos dois terços $(77,16 \%)$ das classes 2,3 e 4 na Figura 2 revela tais situações de enunciação:

1) “Acabo de ser informado que a Fake News da Conferência de Imprensa da Casa Branca de quinta-feira me fez falar e fazer perguntas à Dra. Deborah Birx. Errado, eu estava falando com nosso especialista de laboratório, não Deborah, sobre a luz solar etc. e o coronavírus. A mídia lamestream está corrompida e doente!".

Na classe 1 (vermelho), com apenas $22,84 \%$ dos ST do conjunto de publicações, estão reunidas as palavras em que o ex-presidente destacou suas ações nas áreas sanitária e econômica. É nela que prevalece, mais uma vez, sua defesa do uso de medicamentos cujos resultados não foram comprovados cientificamente, como pode ser constatado em "m":

m) "HIDROXICLOROQUINA E AZITROMICINA, juntos, têm uma chance real de ser um dos maiores viradores de jogo na história da medicina. O FDA moveu montanhas - Obrigado! Esperançosamente, AMBOS ( $\mathrm{H}$ funciona melhor com A, International Journal of Antimicrobial Agents) serão colocados em uso IMEDIATAMENTE. AS PESSOAS ESTÃO MORRENDO, MOVA-SE RAPIDAMENTE, E DEUS ABENÇOE A TODOS!"”.

A presença de palavras como Deus, oração, união, amor, honra, país e a favorita de Trump, great (que mantemos em inglês devido aos diversos significados que ela pode ter dependendo do uso), nessa classe indica a combinação de sentimentos que o então presidente mobilizou em prol dos sentidos que buscou construir sobre sua atuação e a de seu governo na luta contra a pandemia, como pode ser visto em "n", ainda que, muitas vezes, não convirja com os números ascendentes de casos e mortes e a lotação dos hospitais nos Estados Unidos. É um mix de religiosidade e nacionalismo, explorando ao máximo o ufanismo tão marcante no slogan das campanhas ao seu primeiro e segundo mandatos: "Make America Great Again" (em português Torne os Estados Unidos Grande de Novo), em 2016, e “Keep America Great!” (em português Mantenha os Estados Unidos Grande), em 2020:

n) "As pessoas que me conhecem e conhecem a história do nosso País dizem que sou o Presidente mais trabalhador da história. Não sei sobre isso, mas eu trabalho duro e provavelmente fiz mais nos primeiros 3 anos e meio do que qualquer presidente na história. As Fake News odeiam isso!". 
Mas é também nessa classe que são registradas as manifestações que mais contribuem para a desinformação, seja para dizer que deve haver prevalência nos esforços para reerguer a economia em relação aos cuidados sanitários, como nos enunciados "o", "p" e "q", minimizar os riscos da doença ao compará-la a uma simples gripe, a exemplo de "r", ou para qualificar pejorativamente seus oponentes, inclusive através da adjetivação do próprio coronavírus, associando-o à China, a exemplo de "s".

o) "NÃO PODEMOS DEIXAR QUE A CURA SEJA PIOR DO QUE O PRÓPRIO PROBLEMA. AO FINALIZAR O PERÍODO DE 15 DIAS, TOMAREMOS A DECISÃO SOBRE QUE CAMINHO QUEREMOS IR!".

p) "Nosso povo quer voltar a trabalhar. As pessoas vão praticar o distanciamento social e tudo mais, e os idosos serão observados de forma protetora e amorosa. Podemos fazer duas coisas juntos. A CURA NÃO PODE SER Pior (de longe) DO QUE O PROBLEMA! O Congresso DEVE AGIR AGORA. Voltaremos fortes!”.

q) "Lembre-se de que a cura não pode ser pior do que o próprio problema. Cuide-se, fique seguro, use o bom senso!".

r) "Isso é diferente. Muito diferente. Isso é uma gripe. Isso é como uma gripe. [...] E, novamente, quando você tem 15 pessoas, e as 15 em alguns dias vão ser reduzidas a perto de zero".

s) "Aqui estão as MUITAS medidas que o governo Trump realizou para proteger os americanos do vírus chinês nos últimos dois meses e meio".

\subsection{Pronunciamentos de Bolsonaro: "gripezinha ou resfriadinho"}

A análise estatística do IRaMuTeQ sobre os pronunciamentos do presidente brasileiro resultou em 161 ST, 6.248 ocorrências, 1.317 formas, 945 formas ativas e 98 formas suplementares, e a CHD gerou um dendrograma com três classes, exibidas na Figura 3. O volume menor do conteúdo, proporcionando menor número de campos lexicais, explica a menor quantidade de classes em comparação com os pronunciamentos de Trump. 
Figura 3 - Dendrograma de Pronunciamentos de Jair Bolsonaro

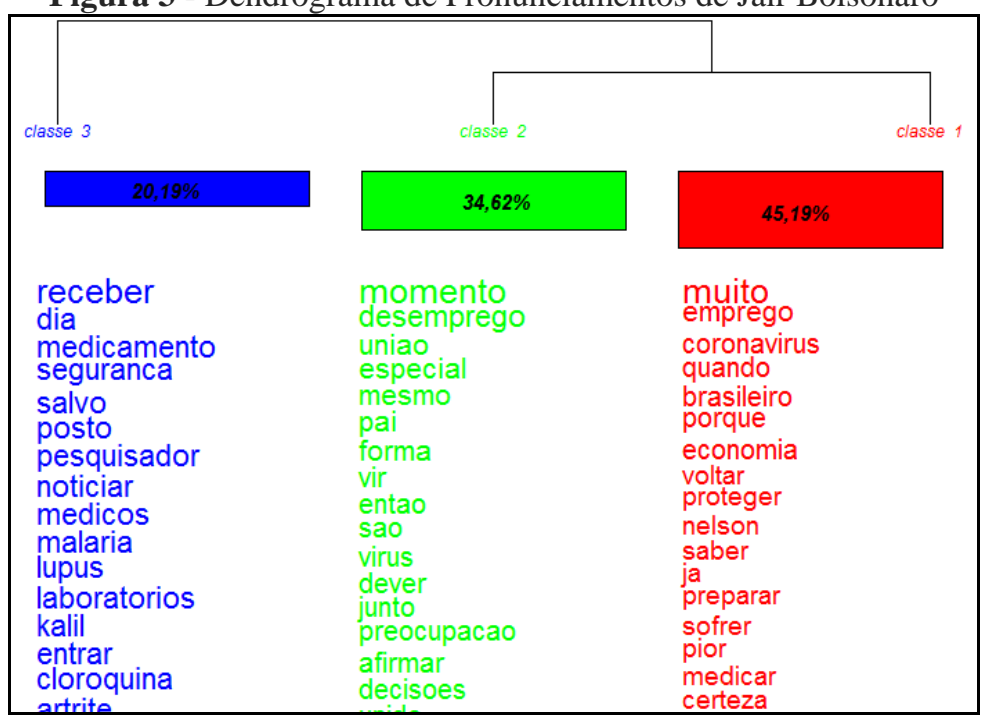

Fonte: Elaborado pelos autores com o IRaMuTeQ (2020).

A conexão entre as classes 1 (vermelho) e 2 (verde) - que, somadas, representam mais de $80 \%$ dos contextos semânticos - retrata o destaque que Bolsonaro deu em suas falas oficiais à falsa oposição entre saúde e economia, reforçada pelo alerta sobre o risco da perda de empregos e redução de salários, como visto no enunciado "t", e à minimização dos efeitos da doença, inclusive tomando a si como exemplo dos poucos danos sobre o corpo, a exemplo de "u". Em "v", a ênfase recai sobre a disputa com os oponentes políticos que ele escolheu, principalmente os gestores de Estados e capitais. Mas no rol dos inimigos também apareceram os presidentes da Câmara dos Deputados e do Senado, o Supremo Tribunal Federal (STF), os partidos de oposição e a imprensa, mesmo que não explicitamente incluídos no enunciado "w":

t) "Nossa vida tem que continuar. Os empregos devem ser mantidos. Devemos, sim, voltar à normalidade".

u) "No meu caso particular, pelo meu histórico de atleta, caso fosse contaminado pelo vírus, não precisaria me preocupar, nada sentiria ou seria, quando muito, acometido de uma gripezinha ou resfriadinho (...)".

v) "Respeito a autonomia dos governadores e prefeitos. Muitas medidas, de forma restritiva ou não, são de responsabilidade exclusiva dos mesmos".

w) "O efeito colateral das medidas de combate ao coronavírus não pode ser pior do que a própria doença”.

A classe 3 (azul, com 20,19\%) tem como principal campo lexical a insistente defesa, por Bolsonaro, do uso de medicamentos - como no caso do 
enunciado " $\mathrm{x}$ " - cuja eficácia nunca foi comprovada. Apesar do dendrograma indicar pouca importância do tema nos pronunciamentos, quando comparadas percentualmente as suas três classes, ele é bem mais frequente nos enunciados do Facebook (como será visto adiante):

x) "Ainda não existe vacina contra ele ou remédio com eficiência cientificamente comprovada, apesar da hidroxicloroquina parecer bastante eficaz".

\subsection{Bolsonaro no Facebook: o discurso sem amarras}

No caso dos enunciados do Facebook, o IRaMuTeQ localizou 434 ST, 17.742 ocorrências, 3.792 formas, 2.992 formas ativas e 2.671 formas suplementares. O dendrograma da Figura 4 demonstra o tratamento dos segmentos de texto com o método da CHD, tendo resultado em 5 classes.

Figura 4 - Dendrograma de Postagens de Jair Bolsonaro

\begin{tabular}{|c|c|c|c|c|}
\hline classe 4 & classe 3 & classe 2 & classe 1 & classe 5 \\
\hline $26,68 \%$ & $24,52 \%$ & $19,47 \%$ & $13,94 \%$ & $15,38 \%$ \\
\hline $\begin{array}{l}\text { falar } \\
\text { republicar } \\
\text { presidente } \\
\text { nao } \\
\text { deus } \\
\text { eua } \\
\text { tudo } \\
\text { link } \\
\text { direito } \\
\text { youtube } \\
\text { serenidade } \\
\text { enfrentar } \\
\text { abencoe } \\
\text { forma } \\
\text { bolsonaro } \\
\text { lei } \\
\text { nresidencia }\end{array}$ & $\begin{array}{l}\text { trabalhador } \\
\text { milhoes } \\
\text { paciente } \\
\text { teste } \\
\text { leito } \\
\text { vao } \\
\text { insumo } \\
\text { empresa } \\
\text { informal } \\
\text { cloroquina } \\
\text { forca } \\
\text { rapidos } \\
\text { continuidade } \\
\text { autonomos } \\
\text { aprovar } \\
\text { anvisa }\end{array}$ & $\begin{array}{l}\text { ministerio } \\
\text { desenvolvim } \\
\text { educacaao } \\
\text { regional } \\
\text { mec } \\
\text { abastecimento } \\
\text { parceria } \\
\text { agricultura } \\
\text { sistema } \\
\text { acesso } \\
\text { enfrentamento } \\
\text { economicos } \\
\text { pecuaria } \\
\text { morar } \\
\text { programa } \\
\text { unico } \\
\text { semiarido }\end{array}$ & $\begin{array}{l}\text { determinar } \\
\text { juro } \\
\text { caixa } \\
\text { emprego } \\
\text { economica } \\
\text { assinar } \\
\text { revogacao } \\
\text { determinacao } \\
\text { contrato } \\
\text { cumprir } \\
\text { federal } \\
\text { maior } \\
\text { salvar } \\
\text { municipios } \\
\text { uniao } \\
\text { governador } \\
\text { mes }\end{array}$ & $\begin{array}{l}\text { santo } \\
\text { sul } \\
\text { rio } \\
\text { mina } \\
\text { grande } \\
\text { obra } \\
\text { mato } \\
\text { catarina } \\
\text { grosso } \\
\text { piaui } \\
\text { espiritar } \\
\text { pernambuco } \\
\text { br116 } \\
\text { geral } \\
\text { entregar } \\
\text { br101 }\end{array}$ \\
\hline
\end{tabular}

Fonte: Elaborado pelos autores com o IRaMuTeQ (2020).

Avesso, no geral, a contatos com jornalistas, Bolsonaro faz das mídias sociais suas principais ferramentas de comunicação. Como também acionou pouco a rede nacional de rádio e TV para pronunciamentos, se comparado com as conferências de imprensa quase semanais de Trump, foi nos diversos sites de rede social onde tem conta que, principalmente, construiu os sentidos sobre a Covid-19, associando-a a significantes como guerra, batalha, luta, tempestade, crise, entre outros. Diferentemente do ex-presidente dos Estados Unidos, o 
brasileiro recorre muito mais a metáforas militares, o que pode ser inferido do seu vínculo profissional anterior com o Exército.

No seu trabalho semiótico via internet, o presidente foi tecendo significados sobre as ações sanitárias e econômicas do seu governo no enfrentamento da pandemia, como fica demonstrado na interligação das classes 1 (vermelho) e 2 (cinza). As disputas de narrativas com outros agentes políticos - que chama de "autoridades" no enunciado "y" - são o destaque da classe 5 (roxo), revelando que o mandatário, a partir da pandemia, reforça ainda mais a polarização que marcou a disputa em que foi eleito em 2018 e já antecipa disputas com possíveis oponentes ao seu desejo de garantir um segundo mandato em 2022:

y) "- O mundo todo foi atingido pelo Coronavírus, pandemia que devemos enfrentar sem ocasionar pânico ou histeria na população, como venho dizendo desde o início. As medidas tomadas pelas autoridades devem ser equilibradas de modo que o efeito colateral não afete o trabalho no Brasil. - A vida em primeiro lugar, mas sem emprego, a sociedade enfrentará um problema tão grave quanto a doença: a miséria".

A classe 3 (verde) associa a crise econômica com a necessidade de revisão das medidas de distanciamento social tomadas pelos governadores sob o argumento de que a cloroquina e outros medicamentos podem fazer as pessoas voltarem ao trabalho, como constatado em "z" e "aa". No Facebook, o tema ganha muito mais destaque, reunido na classe com o segundo maior conjunto de ST $(24,5 \%)$ do dendrograma:

z) "- O tratamento da COVID-19, a base de Hidroxicloroquina e Azitromicina, tem se mostrado eficaz nos pacientes ora em tratamento. - Nos próximos dias, tais resultados poderão ser apresentados ao público, trazendo o necessário ambiente de tranquilidade e serenidade ao Brasil e ao mundo. [...] - Portanto, esses imunizados poderiam circular (trabalhar) livremente com mais tranquilidade, como, por exemplo, profissionais de saúde, segurança, transporte, etc...".

aa) "A Hidroxicloroquina cada vez mais demonstra sua eficácia em portadores do COVID-19. - Tenho recebido relatos de todo o Brasil nesse sentido".

Por fim, a classe 4 (azul) revela os signos que evocam a religiosidade explorada pelo presidente, presente no slogan de sua campanha à presidência ("Brasil acima de tudo, Deus acima de todos"). A referência a palavras como "Deus", “abençoar", "iluminar", entre outras do contexto semântico associado à 
fé, é o modo como Bolsonaro reforça o vínculo com parte importante de seus apoiadores, como na exortação do enunciado "ab":

ab) "Campanha de jejum e oração pelo Brasil”.

\section{Considerações finais}

Ainda que não seja possível afirmar categoricamente que havia um alinhamento acertado intencionalmente entre Donald Trump, ex-presidente dos Estados Unidos, e Jair Bolsonaro, presidente do Brasil, para adotarem as mesmas estratégias de comunicação, a análise aqui empreendida, sobre as operações de informação que os dois acionaram para abordar a Covid-19, mostra que há uma convergência pelo menos intrigante em suas estratégias de desinformação e engodo. Se podem ser relacionadas pelos conteúdos usados, elas confluem também através das formas de enunciação, apesar de suas especificidades nos dois ambientes de comunicação. Vamos a algumas considerações que a análise revelou.

Quando elegem o tema dos medicamentos como solução para a suspensão das medidas de distanciamento, preocupados mais com os impactos da crise econômica sobre suas aspirações a um novo mandato e menos com a saúde de seus compatriotas, Trump e Bolsonaro usam informações que têm a marca da Agnotologia. Consumidas pelos públicos leigos dos dois países, e considerando a força de autoridade que os presidentes têm, as informações deles provocam dúvidas diante das recomendações dadas por especialistas do campo da saúde. Seja quando se baseiam em estudos ainda indefinidos ou resultados imprecisos sobre os efeitos dos remédios para advogarem mudanças e venderem falsas ilusões, ou quando tomam decisões governamentais relacionadas ao tema (o envio da hidroxicloroquina para os Estados, feita por Trump, ou a fabricação do remédio pelo Exército, determinada por Bolsonaro), colaboram com o aprofundamento da desinformação, podendo levar as populações à automedicação e, com isso, ao risco de agravamento de suas saúdes ou à morte.

Mas tal tática está associada ao esforço político, posto em prática igualmente pelos dois presidentes, de estabelecer a falsa oposição entre saúde e 
economia. A habilidade em obter adesão a esse ponto de vista pode significar o apoio, junto a diferentes camadas da sociedade dos dois países, para cobrar a reversão das medidas de distanciamento social implementadas por governadores e prefeitos (apoiadas pelos demais políticos da oposição em ambos países).

Para isso, é preciso transformá-los em inimigos, a quem o povo deve cobrar posteriormente as responsabilidades. Como em qualquer batalha - é assim que Trump e, ainda mais, Bolsonaro semantizam a pandemia -, é preciso deixar claro quem é quem no front. O recurso da polarização, em que, de um lado, estão os bons (neste caso, os dois mandatários e seus apoiadores) e, do outro, os maus (oposição, imprensa, OMS, China, vírus chinês etc.), apenas reforça a lógica que orientou as eleições e o exercício dos dois mandatos, lá e cá.

A recorrência à minimização dos riscos de contágio, dos efeitos da doença e do número de mortes, principalmente nas postagens do Facebook, é uma das marcas principais da similaridade de forma e conteúdo encontrada nas operações informacionais dos dois líderes políticos, caracterizando-se como expressão de um verdadeiro negacionismo da pandemia. Com os enunciados em que comparam a Covid-19 a uma gripe simples e com o menosprezo pelo impacto do coronavírus sobre os seus próprios corpos (ainda que não se refiram à toda estrutura médica e hospitalar que os dois têm as suas disposições), os dois líderes combinam a manipulação e o engano proposital. Tais ardis são ainda mais enfatizados pelos atos individuais dos dois de não usarem máscaras de proteção, registrados através de vídeos e fotografias que circulam na imprensa e em suas próprias mídias sociais.

Essas táticas ganham um tempero a mais quando são embaladas com os discursos em que Trump e Bolsonaro - assumindo-se como leais e reconhecedores da sabedoria do povo, a quem nunca abandonarão, por quem são capazes de fazer esforços incríveis, mas sem demagogia - invocam signos cujos sentidos exploram o patriotismo, o orgulho nacional e o país como uma grande família, e os combinam com os campos semânticos aos quais palavras como Deus, fé, oração e benção estão associadas. Entretanto, nada disso impediu que os dois países assumissem a liderança mundial - o Brasil, logo depois dos Estados Unidos - no número de mortos por Covid-19. Se o uso de estratégias de 
desinformação, como mostram os manuais militares, pode fazer vencer uma guerra, esse não foi o caso com os governos de Trump e Bolsonaro.

Por fim, o estudo conclui que foi possível identificar as seguintes similitudes informacionais entre Trump e Bolsonaro, através da: 1) negação da gravidade do problema; 2) minimização das mortes; 3) posicionamento anticiência; 4) apelo religioso; 5) adoção de solução milagrosa; 6) preocupação com questões que influenciassem a reeleição em detrimento da saúde; 7) divulgação de informações erradas; 8) ataque à mídia; 9) ataque aos governadores e às medidas de isolamento social; 10) intitulação do vírus como inimigo; 11) culpabilização de terceiros pelos problemas (como governadores, prefeitos, China e mídia).

O discurso controverso e as atitudes contrárias às orientações da OMS como a negação da doença, a indicação de remédios sem comprovação científica, o incentivo ao não isolamento social e ao não uso da máscara facial, assim como a minimização dos efeitos (mortes) e a incitação ao medo (desemprego) podem ter contribuído com a desinformação e o comportamento de risco, possibilitando o aumento do contágio da população e até a morte.

\section{Referências}

BARDIN, L. Análise de conteúdo. São Paulo: Edições 70, 2016.

BOURDIEU, P. A economia das trocas linguísticas: o que falar quer dizer. São Paulo: Edusp, 2008.

BRETON, P. A manipulação da palavra. São Paulo: Loyola, 1999.

BRITO, V. DE P.; PINHEIRO, M. M. K. Poder informacional e desinformação. Tendências da Pesquisa Brasileira em Ciência da Informação, João Pessoa, v. 8, n. 2, p. 144-164, 2015.

CAMARGO, B.; JUSTO, A. IRAMUTEQ: um software gratuito para análise de dados textuais. Temas em Psicologia, Ribeirão Preto, v. 21, n. 2, p. 513-518, dez. 2013.

DARNTON, R. El diablo en el agua bendita: o el arte de la calumnia de Luis XV a Napoleón. México, D.F.: FCE - Fondo de Cultura Económica, 2014.

FOUCAULT, M. Microfísica do poder. Rio de Janeiro: Graal, 1979. 
FROEHLICH, T. J. A not-so-brief account of current information ethics: the ethics of ignorance, missing information, misinformation, disinformation and other forms of deception or incompetence. BiD: textos universitaris de biblioteconomia i documentació, Barcelona, n. 39, des. 2017. DOI: https://dx.doi.org/10.1344/BiD2017.39.8. Disponível em: http://bid.ub.edu/en/39/froehlich.htm. Acesso em: 7 jan. 2021.

GERASIMOV, V. The value of science is in the foresight: new challenges demand rethinking the forms and methods of carrying out combat operations. ilitary Review, Leavenworth, KS, v. 96, n. 1, p. 23-29, fev. 2016. Disponível em: https://www.armyupress.army.mil/portals/7/militaryreview/archives/english/militaryreview_20160228_art008.pdf. Acesso em: 23 mar. 2021.

GONZÁLEZ DE GÓMEZ, M. N. Novos cenários políticos para a informação. Ciência da Informação, Brasília, v. 31, n. 1, p. 27-40, jan./abr. 2002.

ORGANIZAÇÃO PAN-AMERICANA DA SAÚDE. Entenda a infodemia e a desinformação na luta contra a covid-19. Washington, D.C.: Organização Pan-Americana da Saúde, 2020. Disponível em: https://iris.paho.org/bitstream/handle/10665.2/52054/FactsheetInfodemic_por.pdf. Acesso em: 10 jun. 2020.

SANTOS NETO, J. A. DOS; ALMEIDA JÚNIOR, O. F. DE. O caráter implícito da mediação da informação. Informação \& Sociedade: Estudos, João Pessoa, v. 27, n. 2, 25 ago. 2017.

TZU, S.; PIN, S. A arte da guerra. São Paulo: WMF Martins Fontes, 2002.

WARDLE, C.; DERAKHSHAN, H. Information disorder: toward an interdisciplinary framework for research and policy making. Strasbourg: Council of Europe, out. 2017.

\title{
Disinformation in the Covid-19 pandemic: informational similarities between Trump and Bolsonaro
}

\begin{abstract}
This empirical research aimed to investigate possible informational similarities between the former president of the United States and the president of Brazil, due to the political-ideological alignment between Donald Trump and Jair Bolsonaro, who had a contradictory position in the fight against Covid-19. In order to elucidate the research question, data were collected from posts on the profiles of presidents on Facebook and official pronouncements on government websites since the first day of notification in countries to carry out Content Analysis through the program IRaMuTeQ, based on the theoretical-conceptual framework on disinformation. The results of the analyzes showed informational similarities between the two presidents, as well as similarities in the
\end{abstract}


controversial speech and in attitudes contrary to the measures advocated by the World Health Organization.

Keywords: Covid-19. Informational similarities. Disinformation.

Recebido: $15 / 08 / 2020$

Aceito: 19/01/2021

\section{Declaração de autoria}

Concepção e elaboração do estudo: Priscila Ramos Carvalho, Paulo César Castro de Sousa, e Marco André Feldman Schneider

Coleta de dados: Priscila Ramos Carvalho e Paulo César Castro de Sousa.

Análise e discussão de dados: Priscila Ramos Carvalho, Paulo César Castro de Sousa, e Marco André Feldman Schneider.

Redação e revisão do manuscrito: Priscila Ramos Carvalho, Paulo César Castro de Sousa, e Marco André Feldman Schneider.

\section{Como citar}

CARVALHO, Priscila Ramos; SOUSA, Paulo César Castro de; SCHNEIDER, Marco André Feldman. Desinformação na pandemia de Covid-19: similitudes informacionais entre Trump e Bolsonaro. Em Questão, Porto Alegre, v. 27, n. 3 , p.15-41, 2021. Doi: http://dx.doi.org/10.19132/1808-5245273.15-41

1 Empregamos o termo para designar uma modalidade de informação deliberadamente enganosa, produzida em forma de matéria jornalística do tipo sensacionalista, isto é, com marcado apelo emocional, veiculada preferencialmente nas redes sociais digitais.

${ }^{2}$ O Dicionário Oxford definiu como um adjetivo "relacionado ou denotando circunstâncias em que os fatos objetivos são menos influentes na formação da opinião pública do que apelos a emoções e crenças pessoais". Disponível em: https://en.oxforddictionaries.com/word-of-theyear/word-of-the-year-2016. Acesso em: 10 jun. 2020.

3 No original: "The very "rules of war" have changed. The role of nonmilitary means of achieving political and strategic goals has grown, and, in many cases, they have exceeded the power of force of weapons in their effectiveness. [...] All this is supplemented by military means of a concealed character, including carrying out actions of informational conflict and the actions of special operations forces."

${ }^{4} \mathrm{Na}$ ausência de tradução exata para essa noção de deception, os autores optam pelo termo em português "decepção". De nossa parte, preferimos manter o termo original, em inglês, pois "decepção", em português, possui significado bastante distinto, o que pode gerar confusão.

5 “[...] designaria um modo de produção informacional dominante em uma formação social, conforme o qual serão definidos sujeitos, instituições, regras e autoridades informacionais, os meios e os recursos preferenciais de informação, os padrões de excelência e os arranjos organizacionais de seu processamento seletivo, seus dispositivos de preservação e distribuição.” (GONZÁLEZ DE GÓMEZ, 2002, p. 34). 
${ }^{6}$ AFP Fact Check. Disponível em: https://factcheck.afp.com/afp-Covid-19-verification-hub. Acesso em: 10 jun. 2020.

${ }^{7}$ Latam Chequea. Disponível em: https://chequeado.com/latamcoronavirusportugues. Acesso em: 10 jun. 2020.

${ }^{8} \mathrm{O}$ método consiste na análise lexical das palavras do corpus. A partir da divisão delas em segmentos de textos, de acordo com suas frequências, e da lematização (que consiste na redução de uma palavra flexionada a sua parte essencial), é produzido um dendrograma, ou seja, um gráfico que exibe um esquema hierárquico das palavras, de acordo com a classe delas.

${ }^{9}$ Todas as citações de falas do ex-presidente que compõem o corpus terão tradução livre nossa, inclusive mantendo o estilo de Trump, com o uso constante de letras maiúsculas e sinais de exclamação. 